\title{
Power output for wheelchair driving on a treadmill compared with arm crank ergometry
}

\author{
H Tropp, K Samuelsson, L Jorfeldt
}

\begin{abstract}
Objectives-The limiting factors with regard to power output available for wheelchair ambulation have not been identified. The aim of the present study was to correlate power output during wheelchair driving with (i) power output and oxygen uptake during arm crank ergometry and (ii) arm muscle strength.
\end{abstract}

Methods-Eleven disabled men were examined for maximal power output $\left(\mathbf{P O}_{\max }\right)$ during wheelchair driving on a treadmill and during arm crank ergometry. Oxygen uptake $\left(\mathrm{Vo}_{2}\right)$ was recorded at submaximal and maximal arm crank ergometry in all men and during submaximal wheelchair driving on a treadmill in four men. Power output during wheelchair driving on a treadmill was measured. Static and dynamic elbow muscle strength was measured isokinetically.

Results-PO $\mathbf{m}_{\max }$ was significantly lower (P<0.001) for wheelchair driving (109 (31) W; mean (SD)) than for arm ergometry (163 (49) W). There was a significant correlation between $\mathbf{P O}_{\max }$ for arm crank ergometry and wheelchair driving $(r=$ 0.73). There was no correlation between $\mathbf{P O}_{\max }$ and elbow strength. The mechanical efficiency was constant for the different levels on the arm crank ergometry test. The submaximal testing showed a consistently lower mechanical efficiency for wheelchair driving than for arm crank ergometry.

Conclusions-It is suggested that the lower level of power output for wheelchair driving is fully explained by the lower mechanical efficiency. Any improvement in power output available for ambulation must be based on wheelchair ergonomics. (Br f Sports Med 1997;31:41-44)

Surgery and

Neurorehabilitation, University Hospital, Linköping

H Tropp

K Samuelsson

Department of Clinical Physiology, Karolinksa Hospital, Stockholm, Sweden

L Jorfeldt

Correspondence to:

H Tropp, Department of

Spine Surgery, University

Hospital, S-581 85

Linköping, Sweden.

Accepted for publication 25 July 1996
Keywords: wheelchair; treadmill; arm crank.

The value of cardiorespiratory exercise for prevention of cardiovascular disease is well documented. ${ }^{12}$ In wheelchair-dependent people, good physical work capacity makes the activities of ordinary daily life possible such as open-air recreation and social life. Investigations into physical capacity are therefore of interest, and many studies have been presented. ${ }^{23}$ These have reported results from arm crank ergometry, ${ }^{4-7}$ wheelchair ergometry, ${ }^{8-10}$ treadmill wheeling, ${ }^{1}$ free-wheeling on the ground, ${ }^{11}$ and rollers. ${ }^{12}$

Wheelchairs have been improved, becoming lighter and more versatile. Physical perform- ance among the disabled has also improved. However, the limiting factors with regard to power output (PO) available for ambulation have not been identified.

The aim of the present study was to correlate power output during wheelchair driving (PO(WC)) with (i) power output and oxygen uptake during arm crank ergometry (PO(AC) and $\mathrm{Vo}_{2}(\mathrm{AC})$ ) and (ii) arm muscle strength.

\section{Methods}

Eleven members of the Swedish national wheelchair basketball team who participated in the European championships took part in the investigation. They were physically active for five to eleven hours a week. Five of them played wheelchair basketball only, and six combined basketball with track and field, table tennis, or shooting. Table 1 lists their disabilities.

Each man was tested in an arm crank ergometer at a rate of $60 \mathrm{rpm}$, seated in his own wheelchair while PO (in W) was recorded. Starting at $50-110 \mathrm{~W}$, increments of $20 \mathrm{~W}$ were used every two minutes. $\mathrm{VO}_{2}$ was directly measured by the argon dilution method using a mass spectrophotometer for the gas analyses. $\mathrm{PO}_{\text {max }}$ and $\mathrm{Vo}_{2 \max }$ were defined as the values at the highest level. Heart rate was determined from the electrocardiogram.

PO(WC) was recorded on a motor-driven treadmill. The drag force $\left(F_{d}\right)$ to be overcome by the subject was measured with a dynamometer with the subject sitting inactive in the wheelchair on the moving treadmill. $F_{d}$ (resistance force at constant speed) is dependent on internal friction, rolling friction, and a gravity component, but is independent of velocity. The inclination of $3^{\circ}$ has been found adequate for trained individuals, and $F_{d}$ at the slope in question was around $50 \mathrm{~N}$, depending on weight and wheelchair. The men used their own chairs. Testing was then carried out at increasing velocities $(0.25 \mathrm{~m} / \mathrm{s}$ every minute) until the subject was unable to drive for one minute. The rate of increase $(12.5 \mathrm{~W}$ per step) seems to be equivalent to the $20 \mathrm{~W}$ step for arm cranking.

$P O$ was calculated as $P O=F_{d} v$, where $\mathrm{v}=$ velocity. $\mathrm{PO}_{\max }$ was the highest workload achieved.

Table 1 Disabilities of the wheelchair-dependent subjects

\begin{tabular}{ll}
\hline Type of disability & Number of subjects \\
\hline Poliomyelitis & 3 \\
Cerebral palsy & 2 \\
Lower limb amputation & 2 \\
Paraplegia (thoracic level) & 3 \\
Tetraplegia (cervical level) & 1 \\
\hline
\end{tabular}


Table 2 Maximal aerobic testing

\begin{tabular}{|c|c|}
\hline Number of subjects & 11 \\
\hline Mean (SD) age (years) & $30(6)$ \\
\hline Mean (SD) weight $(\mathrm{kg})$ & $64(14)$ \\
\hline $\mathrm{PO}_{\max }(\mathrm{AC})(\mathrm{W})$ & $163(49)$ \\
\hline $\mathrm{PO}_{\max }$ weight(AC) $(\mathrm{W} / \mathrm{kg})$ & $2.55(0.43)$ \\
\hline HR (AC) (beats $/ \mathrm{min}$ ) & 185 (17) \\
\hline $\mathrm{Vo}_{2 \max }(\mathrm{AC})(\mathrm{ml} / \mathrm{kg} / \mathrm{min})$ & $38(6)$ \\
\hline $\mathrm{Vo}_{2 \max }(\mathrm{AC})-\mathrm{BMR}(\mathrm{ml} / \mathrm{kg} / \mathrm{min})$ & $34(6)$ \\
\hline $\mathrm{ME}_{\max }(\mathrm{AC})(\%)$ & $22(2)$ \\
\hline $\mathrm{PO}_{\max }(\mathrm{WC})(\mathrm{W})$ & $109(31)$ \\
\hline $\mathrm{PO}_{\max } /$ weight $(\mathrm{WC})(\mathrm{W} / \mathrm{kg})$ & $1.72(0.37)$ \\
\hline
\end{tabular}

$\mathrm{R}=$ heart rate; $\mathrm{BMR}=$ basic metabolic rate

Net mechanical efficiency (ME), as calculated from $V_{2}$, is assumed to reflect the efficiency of work. Because working for one minute at $1 \mathrm{~W}$ is equivalent to $60 \mathrm{~J}$, and because each litre of oxygen used is equivalent to about $20934 \mathrm{~J}, \mathrm{ME}$ (\%) can be roughly calculated as:

$$
\mathrm{ME}(\%)=\frac{60 \times \mathrm{PO}}{20934 \times \mathrm{VO}_{2}} \times 100
$$

$\mathrm{Vo}_{2}$ was corrected for calculated basal metabolic rate. ${ }^{13} \mathrm{ME}$ was calculated for all levels of arm crank testing. Four men were randomly selected for investigation of $\mathrm{ME}$ at one submaximal level of wheelchair driving (60 W) for three minutes. The results were compared with the same level of the incremental arm cranking test. The Douglas bag technique in combination with the argon dilution method was used to measure expired air volumes and $\mathrm{VO}_{2}$ during wheelchair driving on the treadmill

Static and dynamic muscle strength for concentric elbow extension and flexion was measured isokinetically at 0,30 , and $180 \%$ angular velocity, in accordance with common principles. ${ }^{14}$

\section{STATISTICAL ANALYSIS}

Data are presented as mean (SD) values. Linear regression analysis was used to study the relations between different variables. Because the linear regression line did not pass through the origin, we also tested a non-linear regression $y=a_{0}+a_{1} x+a_{2} x^{2}$. The $F$ test was used to compare variances. Variation within the group was defined as SD/mean ratio. For the paired data, Student's $t$ test (paired samples) was used, checked by sign and rank sum tests

\section{Results}

Table 2 shows the results for maximal aerobic testing. $\mathrm{PO}_{\max }$ was consistently lower for wheelchair driving than for arm cranking $(P<0.001)$. Linear regression analysis showed a significant correlation between $\mathrm{PO}_{\max }$ for the two types of work. Figure 1 shows the second degree polynomial regression $(r=0.73)$ together with the line of identity. The linear regression forced through the origin gave $r=0.61$, with $k=0.67$ describing the relation between values of $\mathrm{PO}_{\max }$ for the two types of work.

The correlation coefficient for the regression of $\mathrm{PO}_{\max }(\mathrm{WC})$ on $\mathrm{Vo}_{2}$ was higher $(\mathrm{r}=0.77)$, but the residual variance was not significantly lower.

Figure 2 shows the results for isokinetic muscle strength. There was no significant cor-

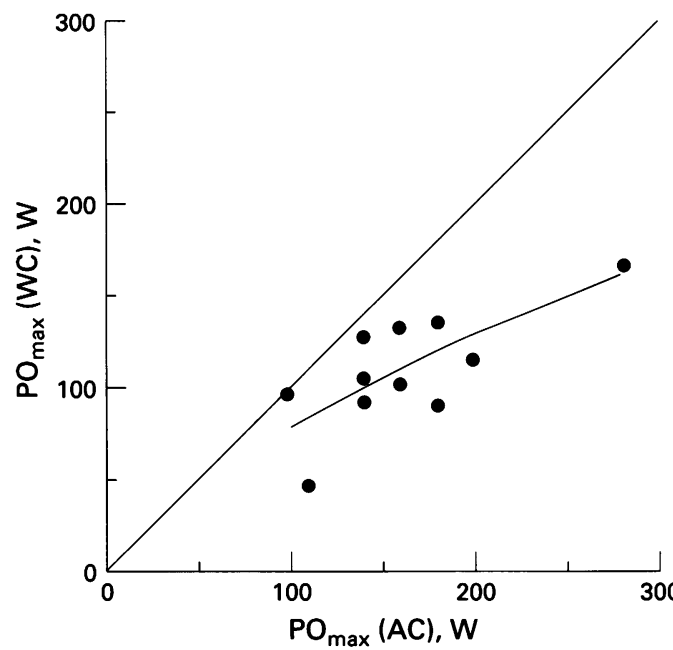

Figure 1 The relation between $P_{\text {max }}$ during arm cranking and wheelchair driving on the treadmill $(y=24$ $+0.58 x-0.00032 x^{2} ; r=0.73, S D_{r e s}=24$ ).

relation between $\mathrm{PO}_{\max }$ and arm muscle strength for concentric elbow flexion/extension measured at different angular velocities $(r=$ $0.10-r=0.55$ ).

$\mathrm{PO}_{\max }$ was highly correlated with weight ( $r=$ 0.620 for WC and $r=0.804$ for AC). The variation within the group expressed as $\mathrm{SD} /$ mean was lower if $\mathrm{PO}_{\max }$ was presented relative to body weight $(0.22$ and 0.17 for WC and $\mathrm{AC}$ respectively) instead of in absolute ( 0.30 and 0.28 ) values.

Maximum heart rate during arm cranking was lowest for the man with tetraplegia (cervical lesion at C7-C8 level) which reached 150 beats/min. This man also showed the lowest quotient for $\mathrm{PO}_{\max }(\mathrm{WC}) / \mathrm{PO}_{\max }(\mathrm{AC})$ (0.42).

The ME was constant for each individual for the different levels on the arm crank test. Submaximal testing (table 3 ) showed a consistently lower ME for wheelchair driving than for arm cranking. The relations were the same as for the quotient $\mathrm{PO}_{\max }(\mathrm{WC}) / \mathrm{PO}_{\max }(\mathrm{AC})$.

In the small group of four, the correlation between $\mathrm{PO}_{\max }$ during the two types of work at the maximum aerobic test showed an $r$ value of 0.127 . If the $M E$ values found in the submaximal test were used for each individual to calcu-

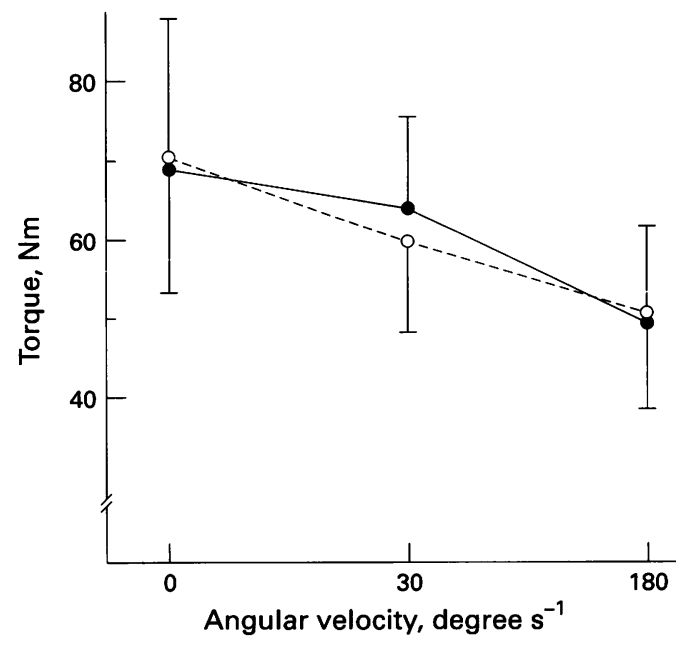

Figure 2 Isokinetic muscle strength (peak torque, $N$, mean $(S D))$, for arm flexion ( $(\bullet)$ and extension (O). 
Table 3 Submaximal aerobic testing

\begin{tabular}{ll}
\hline Number of subjects & 4 \\
$\mathrm{PO}(\mathrm{W})$ & $60(11)$ \\
$\mathrm{Vo}_{2}$ (AC) (litres/min) & $1.09(0.19)$ \\
$\mathrm{ME}$ (AC) (\%) & $20(2)$ \\
$\mathrm{Vo}_{2}$ (WC) (litres/min) & $1.51(0.22)$ \\
$\mathrm{ME}(\mathrm{WC})(\%)$ & $13(1)$ \\
\hline
\end{tabular}

late a theoretical $\mathrm{VO}_{2 \max }$ (not obtained during the initial test), the $r$ values between $\mathrm{Vo}_{2 \max }$ on the two tests were as high as 0.995 and did not differ $(P<0.09)$.

\section{Discussion}

We have found lower $\mathrm{PO}_{\max }$ and $\mathrm{ME}$ during wheelchair driving on a treadmill as compared with arm crank ergometry. There are several differences between the ergonomics during arm cranking and wheelchair driving. Wheelchair driving requires active trunk stabilisation and withdrawal of the hand. This entails inertial energy losses due to acceleration and deceleration of body parts, which might explain why the second degree polynomial does not improve the correlation. The power production in the wheelchair is probably related to energy losses not proportional to PO.

An interesting aspect of these results is their potential for improving wheelchairs, thereby affecting mobility of disabled patients. It is obvious that wheelchair driving, requiring the motion of body parts, is energy consuming compared with the arm crank, which has counter movements and no withdrawal phases. The low $\mathrm{ME}$ is a direct measure of power utilisation of work for the purpose of mobility. The energy needed for non-propulsive aims should be decreased.

Arm-cranking styles of wheelchairs are available, but have too many negative characteristics. Additional biomechanical analysis of energy transfer between body parts resulting in propulsion should be performed if a more efficient power production directed at ambulation is to be achieved. Such an analysis could determine where energy is lost during transmission to the rims of the wheelchairs.

In the treadmill wheelchair driving test, the velocity rather than the $\mathrm{PO}_{\max }$ might have been the factor causing subjects to stop. However, the maximum velocity of $2.2(0.4) \mathrm{m} / \mathrm{s}$ is no problem for this group of subjects.

Gass and Camp ${ }^{15}$ found a higher $\mathrm{Vo}_{2}$ capacity for wheelchair driving on a treadmill than for arm cranking. McConell et al, ${ }^{16}$ on the other hand, found that maximal $\mathrm{Vo}_{2}$ was equivalent for wheelchair driving on a treadmill and arm crank ergometry. In these studies neither PO nor ME was measured.

ME for arm ergometry in people with paraplegia is about $20 \%{ }^{17}{ }^{18}$ - that is, only slightly lower than for walking ${ }^{19}$ and cycling. ${ }^{20}{ }^{21}$ On the other hand, $\mathrm{ME}$ for handrim wheelchairs rarely exceeds $10 \% .{ }^{82}$ Our data are in accord with this. Brattgard et al reported that wheelchair driving involves lower productive energy expenditure than does arm cranking. They reported an $\mathrm{ME}$ of $17.7 \%$ for arm cranking and $8.1 \%$ in the wheelchair ergometer.
Our method for testing wheelchair driving is based on measurement of $F_{d}$, which is constant at different speeds but depends upon rolling resistance, internal friction, and gravity. Outdoors the $F_{d}$ also includes wind resistance, but otherwise the method is valid because of the direct measurement. The $F_{d}$ is independent of posture and inertia over time.

In this study there was a corresponding ratio between wheelchair driving and arm cranking for $\mathrm{ME}$ and $\mathrm{PO}_{\max }$. $\mathrm{ME}$ was strongly significant for the relation between $\mathrm{PO}_{\max }$ for the two types of work. We suggest that low $M E$ is the main reason for low $\mathrm{PO}_{\max }$ during wheelchair driving. In this paper and in McConnell et al, ${ }^{16}$ $\mathrm{VO}_{2 \max }$ is found to be the same for both arm modalities, and thus the energy consumption is the same. Since ME differs between wheelchair and non-wheelchair users, ${ }^{22}$ but also for exercise on different prototypes of chairs, we believe it may prove useful in understanding and improving wheelchairs.

Wicks $e t a l^{11}$ studied athletes with spinal cord injury, but their figures for PO during wheelchair ergometry seem to be very low. $\mathrm{PO}_{\max }$ for a group comparable with our subjects (4 in the International Classification) was very low, although arm crank values and muscle strength did not differ to that extent from those of our subjects. The relationship wheelchair ergometry/arm cranking was only $36 \%$. This can be explained by the different and rather unphysiological testing situation. Testing in the rigid wheelchair ergometer may not take into account such factors as balance and torso stabilisation, and these are particularly important when testing the disabled. A change in centre of gravity is seen very clearly during tests on the treadmill. When the subject leans forward the chair slows down, and on extension of the trunk the chair moves forward. The centre of gravity is held at a constant speed. When $F_{d}$ is measured the subject is sitting passively on a moving treadmill. If the subject is asked to perform postural movements similar to those of active propulsion, one can see a sinusoidal variation in $F_{d}$. Mechanically, these motions are partly transferred to the chair. With a rigid ergometer all such postural energy is lost. The rigid ergometer only measures power transferred to the cranking device. Treadmill testing seems to be a preferable method because it measures all energy transfer from subject to chair movement.

Hildebrand et $a l^{23}$ indicated that the normal daily locomotor patterns of wheelchair dependent individuals are insufficient to maintain or improve fitness levels. Burke $e t$ a $l^{4}$ showed in a study on four wheelchair basketball players that the average $\mathrm{Vo}_{2}$ during play was $78 \%$ of $\mathrm{VO}_{2 \max }$ during arm crank testing; these figures meet the guidelines for improvement of cardiovascular function. The figures of Burke et al, together with the high $\mathrm{PO}_{\max }$ found in our subjects, five of whom engaged in no other type of physical exercise, suggest that wheelchair basketball is effective for endurance training.

Even if $\mathrm{PO}_{\max }$ for arm cranking and wheelchair driving show a significant correlation, arm cranking values cannot be directly applied 
to wheelchair driving in disabled subjects. Neither can physical training in the form of arm cranking directly be transferred to wheelchair driving. The level of correlation as well as the ratio between the capacity for the two modalities of arm work probably depend on the handicap and state of physical fitness, but may also be explained by the wheelchairs. Our lowest values for the $\mathrm{PO}(\mathrm{WC}) / \mathrm{PO}(\mathrm{AC})$ ratio were those for the two men with the most proximal lesions. The low maximal heart rate for the man with cervical injury is probably explained by the lack of sympathetic cardiac innervation. The particularly low $\mathrm{PO}_{\max }$ (WC) compared with $\mathrm{PO}_{\max }(\mathrm{AC})$ might be due to the trunk instability and weakness, which affects arm cranking less than wheelchair driving. If an evaluation of wheelchair driving capacity based on arm crank ergometry results is carried out, it seems better to use $\mathrm{Vo}_{2}$ data because of the better correlation with $\mathrm{PO}_{\max }(\mathrm{WC})$. However, the value of this type of evaluation seems uncertain. If wheelchair ambulation is required, it will be inadequate to evaluate indirect variables such as $\mathrm{Vo}_{2}(\mathrm{AC})$ and $\mathrm{PO}_{\max }(\mathrm{AC})$. Further studies aimed at improving wheelchair performance should include basic physiological testing, but should also take different diagnoses and disability patterns into consideration.

This investigation was supported by grants from the Swedish Medical Research Council (project no. 04139), the Swedish Sports Research Council, the County of Östergötland Research Council and the Queen Silvia Foundation.

1 Froelicher VF, Brown P. Exercise and coronary hear disease. Fournal of Cardiac Rehabilitation 1981;1:227-8.

2 Kottke TE, Caspersen CJ, Hill CS. Exercise in the management and rehabilitation of selected chronic diseases. Prev Med 1984;13:47-65.

3 Dreisinger TE, Londeree BR. Wheelchair exercise: a review. Paraplegia 1982;20:20-34.

4 Bar-Or O, Inbar O, Spira R. Physiological effects of a sports rehabilitation program on cerebral palsied and postpoliomyelitic adolescents. Med Sci Sports 1976;8:157-61.

5 Ekblom B, Lundberg A. Effect of physical training on adolescents with severe motor handicaps. Acta Pediatrica Scand 1968;57:17-23.
6 Sawka MN, Glaser RM, Wilde SW, von Luhrte TC. Metabolic and circulatory responses to wheelchair and arm crank exercise. $\mathcal{F} \mathrm{Appl}$ Physiol 1980;49:784-8.

7 Sawka MN, Glaser RM, Laubach LL, Al-Samkari O, Suryaprasad AG. Wheelchair exercise performance of the young, middle-aged, and elderly. F Appl Physiol 1981;50 824-8.

8 Brattgård SO, Grimby G, Hook $\mathrm{O}$. Energy expenditure and heart rate in driving a wheelchair ergometer. Scand $\mathscr{f}$ Rehabil Med 1970;2:143-8.

9 Glaser RM, Sawka MN, Brune MF, Wilde SW. Physiological responses to maximal effort wheelchair and arm crank ergometry. $\mathcal{F}$ Appl Physiol 1980;48:1060-4.

10 Sedlock DA, Knowlton RG, Fitzgerald PI. The effects of arm crank training on the physiological responses to submaximal wheelchair ergometry. Eur $\mathcal{f} A p p l$ Physiol 1988;57:55-9.

11 Rhodes EC, McKenzie DC, Coutts KD, Rogers AR A field test for the prediction of aerobic capacity in male paraplegics and quadriplegics. Canadian fournal of Applied Sports gics and quadriplegics.

12 Coutts KD, Rhodes EC, McKenzie DC. Maximal exercise responses of tetraplegics and paraplegics. $\mathcal{F}$ Appl Physio 1983;55: 479-82.

13 Harris AJ, Benedict FG. A biometric study of basal metabolism. Carnegie Institute Washington, publication No 279 Washington DC, 1919.

14 Isolated joint testing $\mathcal{E}$ exercise. A handbook for using Cybex II and U.B.X.T. New York: Lumex Inc, 1980

15 Gass GC, Camp EM. The maximum physiological responses during incremental wheelchair and arm cranking exercise in male paraplegics. Med Sci Sports Exerc 1984;16:355-9.

16 McConnell TJ, Beutel-Horvat TA, Golding LA, Horvat MA. A comparision of wheelchair treadmill ergometry and arm crank ergometry in measuring maximum performance capabilities of male paraplegics (abstract). Med Sci ance capabilities of male

17 Nilsson S, Staff PH, Pruett EDR. Physical work capacity and the effect of training on subjects with long-standing paraplegia. Scand F Rehabil Med 1975;7:51-6.

18 Pugh LGCE. The influence of wind resistance in running and walking and the mechanical efficiency of work agains horizontal or vertical forces. F Physiol (Lond) 1971;213 255-76.

19 Knowlton RG, Fitzgerald PI, Sedlock DA. The mechanical efficiency of wheelchair dependent women during wheelchair ergometry. Canadian fournal of Applied Sports Science $1981 ; 6: 187-90$.

20 Whipp BJ, Seard C, Wasserman K. Oxygen deficit: oxygen debt relationships and efficiency of anaerobic work. $\mathcal{F} A p p l$ Physiol 1970;28:452-6.

21 Wicks JR, Oldridge NB, Cameron BJ, Jones NL. Arm cranking and wheelchair ergometry in elite spinal cord cranking and wheelchair ergometry in elite

22 Woude LHV van der, de Groot G, Hollander AP, van Ingen Schenau GJ, Rozendal R. Wheelchair ergonomics and physiological testing of prototypes. Ergonomics 1986;29. 1561-73.

23 Hildebrandt G, Voigt Ed, Bahn D, Berendes B, Kroger J. Energy costs of propelling a wheelchair at various speeds cardiac response and steering accuracy. Arch Phys Med Rehabil 1970;51:131-6.

24 Burke EJ, Auchinachie JA, Hayden R, Loftin JM. Energy cost of wheelchair basketball. The Physician and Sports Medicine 1985;13:99-105. 